\title{
Stopping Sequence Optimization Analysis of the Combination of Caving Method and Filling Method Based on the Stability of the Contact Zone ${ }^{1}$
}

\author{
Mingxu Wang ${ }^{1}$, Mengguo $\mathrm{Xu}^{1}$ \\ 1 Wuhan University of Science and Technology, School of Resource and Environmental \\ Engineering, Wuhan, Hubei 430081, China; \\ E-mail: mingxuwang@sina.cn
}

\begin{abstract}
Keywords: Non-pillar sublevel caving method; Filling method; Contact zone; Combined mining; Recovery sequence; Simply supported beam; Spring restraint
\end{abstract}

Abstract. Non-pillar sublevel caving mining method is in advancing deep, shallow left lots of safety pillars. It needs to adopt the filling method to improve the recovery for reasonable use of these mineral resources. So, there are two methods of mining occurring together. To ensure the stability of the contact zone of non-pillar sublevel caving mining method and filling method, it is required to select the reasonable filling method to improve the recovery. At the same time, it is the combined mining of non-pillar sublevel caving mining method and filling method coordinately, and to optimize the stopping sequence of the two mining methods. For this reason, packing as energy storage and stress transfer effect, and simplifying the joint exploitation of contact zone to the mechanical model of beam and spring constraint for the calculation of shear stress and deflection, quantitative analysis of the contact zone of stress and strain. By using numerical simulation software, choose the typical profile of Chengchao Iron to simulate, set series monitoring in the contact zone, judge the stopping sequence through the principal strain values, upward horizontal slice stopping and backfilling method is suitable for the mining safety pillar. By means of further analyzing the impact of the combined mining of different stopping sequence on the contact zone, Optimize the stopping sequence in the case of joint exploration, to provide the reference for similar laboratory simulation test and field test, to provide guidance for mining field mining operations.

The research adapted the combined mining of filling method and caving method. Mingsong Pei ect. [1] studied two kinds of mining methods under the coexistence of the surface deformation law through the analog simulation test in laboratory. Fuding Mei ect. ${ }^{[2]}$ was in the upper and bottom pillar sublevel caving mining, and the lower part is cohesive zone of filling stopping, cohesive zone thickness of 40 meters was determined through the numerical simulation, using two methods of mining is safe. Lei Deng ect. ${ }^{[3]}$ divided the transition section of the Chengchao Iron Refinery Caving Method to Filling Method into security pillar and filling mining area, with safety pillar divided into safety pillar and vertical safety pillar among them. Bin Jiang ect. ${ }^{[4]}$ used shallow hole shrinkage stopping which was made between flat-back cut and fill recycling ore to improve the ore recovery and reduce the dilution rate. Researches for the combined mining stopping sequence are less, but the study about the stopping sequence under separate mining methods. Such as filling stopping sequence in the study, Wenbin Xu ect. ${ }^{[5]}$, Zhiliang He ect. ${ }^{[6]}$, Chi Zhang ${ }^{[7]}$, Bin Han ect. ${ }^{[8]}$, Long An ect. ${ }^{[9]}$, Biyong Zhu etc. ${ }^{[10]}$, Yicheng Ye etc. ${ }^{[11]}$, Liangliang Zhou ${ }^{[12]}$, Mengguo Xu etc. ${ }^{[13]}$ and Liguan Wang etc. ${ }^{[15]}$ studied the model of stopping sequence in non-pillar sublevel caving mining method. These studies just involve two mining methods. The first is a selection of mining method in a transitional phase, from non-pillar sublevel caving mining method to filling method in translation, and the research of the isolation layer thickness has problems mostly. The second is no need to consider the problem of mining. This article is about the stopping sequence optimization analysis of the combination of caving method and filling method based on the stability of the contact zone.

When Chengchao Iron mine in non-pillar sublevel caving mining method, for the safety of the mill plant, it will leave safety pillars in the fall line within the west where have a large amount of

\footnotetext{
${ }^{1}$ Author introduction: Wang Mingxu , male, borned in $1986, \mathrm{PhD}$, mainly engage in mining and geotechnical engineering research. E-mail: mingxuwang@sina.cn
} 
magnetite ore. Tighter with resources and making full use of mineral resources, we need to stopping, for this part of the ore. We set aside the safety pillar in the west of 33 exploration line, for protecting the west end surface concentrator and the other construction. At present, mine - 360m $390 \mathrm{~m}$ level pillar in the filling method, and- 360m $\sim 430 \mathrm{~m}$ level pillar in the horizontal layered filling method. At the same time, set up annual filling capacity of 500000 tons of filling system in the west end surface of the earth, whose filling roadway is in $-290 \mathrm{~m}$ level and filling pipeline has been extended to $-360 \mathrm{~m}$ level. The level of safety pillar mining is in $-377.5 \mathrm{~m}$ now. But with the increase of mining depth, the safety pillar of ownership is growing. For utilizing mineral resources rational, we need stopping the safety pillar. In view of the safety of Mill plant in surface, we mine in filling method only. But now Chengchao Iron above $-500 \mathrm{~m}$ levels mine in non-pillar sublevel caving mining method, there is a situation that caving mining is in filling method and non-pillar sublevel caving mining method at the same time. The safety pillar stopping is required to ensure the stability of the earth's surface, and coordinate with non-pillar sublevel caving mining method. We need to specifically study on the filling mining of the safety pillar stopping. To further clear the concrete filling mining method and stopping sequence and the coordination combined mining with non-pillar sublevel caving mining method.

\section{Mechanical model of combined mining in the contact zone}

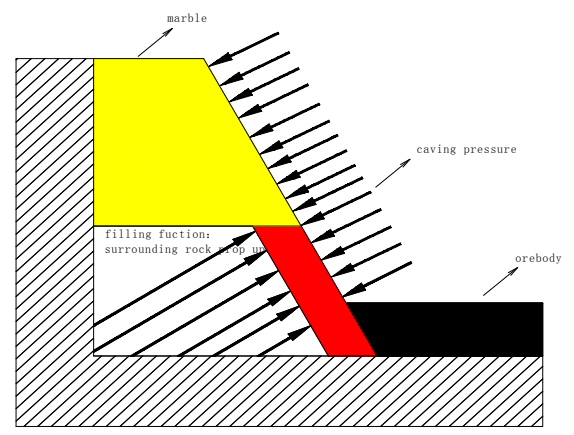

Fig.1 Contact zone mechanics sketch of combined method

In this model, the main role of excavating and filing the filing body is to pass the concentrated stress of the contact zone to surrounding rocks on three sides, and this can serve to support the rocks as well as constraint them.. The marble and ore-bearing rock at the both ends of the contact zone can be simplified as simply-supported beams, so the model in figure 1 can be simplified as a mechanical model which consists of the beam and the spring in the model of the simply supported beam with intermediate spring constraints (Fig.2), to calculate the deflection of any point on the beam and the shear stress.

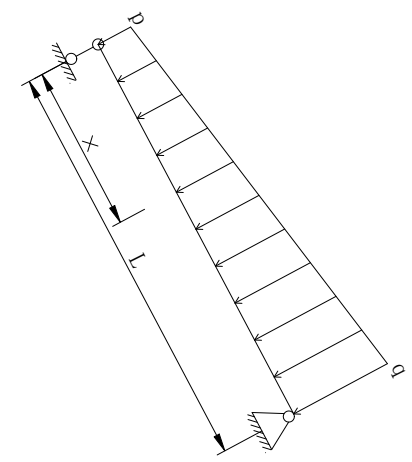

Fig.2 Mechanics model of simply supported beam

For the convenience of calculation, trapezoidal load can be divided into uniformly distributed load and maximum load for $\mathrm{p}$ to $\mathrm{q}-\mathrm{p}$ triangular load. Take a section of the shear:

$$
\mathrm{V}=-\frac{(\mathrm{q}-\mathrm{p})}{2 \mathrm{~L}} \mathrm{x}^{2}+\frac{(\mathrm{q}-2 \mathrm{p}) \mathrm{L}}{6}-\mathrm{p}
$$

In the Ritz method, The role of simply supported beam under uniform distributed load $\mathrm{p}$ at any cross section location deflection ${ }^{[16]}$ : 


$$
\mathrm{w}_{1}=\frac{\mathrm{pL}^{2} \mathrm{x}}{24 \mathrm{EI}}(\mathrm{L}-\mathrm{x})+\frac{\mathrm{px}^{2}}{24 \mathrm{EI}}(\mathrm{L}-\mathrm{x})^{2}
$$

The Simply supported beam is triangle load by triangle, the bending moment is produced by the maximum $\mathrm{q}-\mathrm{p}$ any section placed separate action alone:

$$
M_{1}(\mathrm{x})=-\frac{\mathrm{q}-\mathrm{p}}{6 \mathrm{~L}} \mathrm{x}^{3}+\frac{(\mathrm{q}-\mathrm{p}) \mathrm{L}}{6} \mathrm{x}
$$

According to the approximate differential equation of flexural:

$$
\frac{\mathrm{d}^{2} \mathrm{w}}{\mathrm{dx}^{2}}=\frac{\mathrm{M}}{\mathrm{EI}}
$$

So the simply supported beam is triangle load by triangle, the bending moment is produced by the maximum $\mathrm{q}-\mathrm{p}$ any section placed separate action alone:

$$
\mathrm{w}_{2}=-\frac{\mathrm{q}-\mathrm{p}}{120 \mathrm{LEI}} \mathrm{x}^{5}+\frac{(\mathrm{q}-\mathrm{p}) \mathrm{L}}{36 \mathrm{EI}} \mathrm{x}^{3}
$$

In bending deformation principle of superposition method, the deflection produced by the simply supported beam in the trapezoid loads at any cross section:

$$
\mathrm{w}=\mathrm{w}_{1}+\mathrm{w}_{2}=-\frac{\mathrm{q}-\mathrm{p}}{120 \mathrm{LEI}} \mathrm{x}^{5}+\frac{\mathrm{p}}{24 \mathrm{EI}} \mathrm{x}^{4}+\frac{(\mathrm{q}-4 \mathrm{p}) \mathrm{L}}{36 \mathrm{EI}} \mathrm{x}^{3}+\frac{\mathrm{qL}}{24 E I} \mathrm{x}
$$

Type of $\mathrm{L}$ is for the beam span, $\mathrm{E}$ is for beam of the modulus of elasticity, $\mathrm{I}$ is for a moment of inertia of the beam section.

Considering the actual situation, the existence of stress will be apparently concentrated in the process of mining operation, we can also place a concentrated load $\mathrm{F}$ at any place of the beam. So this beam on the load is a load changing with the $\mathrm{x}$ axis set degrees $\mathrm{F}(\mathrm{x})$. At the same time, different parts of the contact zone have different rock mechanical properties and moment of inertia, the flexural rigidity EI ( $\mathrm{x}$ ) of the beam is Changes in stiffness changing with the $\mathrm{x}$ axis, and finally the mechanical model is as followed in figure 3.

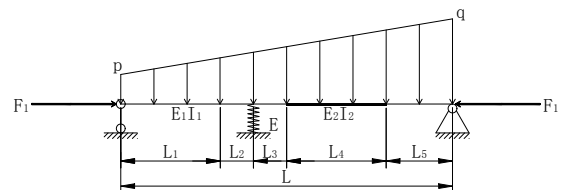

Fig.3 Elastic Constraint Mechanics Model of Simply Supported Beam

When the contact zone is dealt with as a simply-supported beam, he beam can be set as stiffness degree when rocks of beam in different paragraphs have different mechanical properties and sizes, which is to say the beam stiffness should change with the $\mathrm{X}$ axis. When the filling body is small or in the middle of hardening, it can be studied as a elastomer. In the simplified mechanical model, filling body can be studied as a elastomer. When the deformation of filling body is larger or $\mathrm{n}$ the later period of hardening, it can be studied as a elastic-plastic body. The strength of the confining pressure reached more than $20 \mathrm{MPa}$, while the strength of filling body is generally about 2-4 MPa, so in the mechanism of it, the filing body should be dealt with as a soft rock. Also, considering the deformation, the visco-elastoplastic model should be applied here.

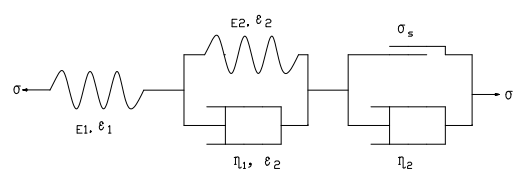

Fig.4 Visco-elastoplastic mode

Constitutive equation:

$$
\begin{gathered}
\text { When } \sigma<\sigma_{\mathrm{s}} \quad \frac{\eta_{1}}{\mathrm{E}_{1}} \dot{\sigma}+\left(1+\frac{E_{2}}{E_{1}}\right) \sigma=\eta_{1} \dot{\varepsilon}+E_{2} \varepsilon \\
\text { When } \sigma \geq \sigma_{\mathrm{s}} \quad \ddot{\sigma}+\left(\frac{E_{2}}{\eta_{1}}+\frac{E_{2}}{\eta_{2}}+\frac{E_{1}}{\eta_{1}}\right) \dot{\sigma}+\frac{E_{1} E_{2}}{\eta_{1} \eta_{2}}\left(\sigma-\sigma_{s}\right)=E_{2} \ddot{\varepsilon}+\frac{E 1 E 2}{\eta_{1}} \dot{\varepsilon}
\end{gathered}
$$


Creep equation:

$$
\begin{gathered}
\text { When } \sigma<\sigma_{\mathrm{s}} \quad \varepsilon=\frac{\sigma_{0}}{\mathrm{E}_{1}}+\frac{\sigma_{0}}{\mathrm{E}_{2}}\left(1-\mathrm{e}^{\frac{-E_{2}}{\eta_{1}} t}\right) \\
\text { When } \sigma \geq \sigma_{\mathrm{s}} \quad \varepsilon=\frac{\sigma_{0}}{\mathrm{E}_{1}}+\frac{\sigma_{0}}{\mathrm{E}_{2}}\left(1-\mathrm{e}^{\frac{-E_{2}}{\eta} t}\right)+\frac{\sigma_{0}-\sigma_{s}}{\eta_{s}} t
\end{gathered}
$$

Type of $\sigma_{\mathrm{s}}$ is for the traction resistance of the friction plate.

\section{The options of fill stoping schemes}

We will do the research of numerical simulation firstly, and then choose to do a similar simulation experiment with typical profiles. First of all, we have some relevant geological dates of mine, and also do a geology survey on this area. Meanwhile, we have carried on the corresponding sample and do the experiment of rock physical and mechanical properties. For convience, we process the experimental results appropriately, and determine the physical and mechanical parameters of simulation Rock involved in the study area, which shown in table 1.

Table 1 Physical and mechanical parameters of typical ore

\begin{tabular}{llllllll}
\hline Litho logy & $\begin{array}{l}\text { Modulus of } \\
\text { elasticity } \\
/ \mathrm{GPa}\end{array}$ & $\begin{array}{l}\text { Poisson's } \\
\text { ratio }\end{array}$ & $\begin{array}{l}\text { Bulk } \\
\text { density } \\
/ \mathrm{kN} \cdot \mathrm{m}^{-3}\end{array}$ & $\begin{array}{l}\text { Compressive } \\
\text { strength } \\
/ \mathrm{MPa}\end{array}$ & $\begin{array}{l}\text { Tensile } \\
\text { strength } \\
/ \mathrm{MPa}\end{array}$ & $\begin{array}{l}\text { Cohesive } \\
\text { force } \\
/ \mathrm{MPa}\end{array}$ & $\begin{array}{l}\text { Angle } \\
\text { of } \\
\text { internal } \\
\text { friction } \\
/\left(^{\circ}\right)\end{array}$ \\
\hline Plate on the rock & 31.2 & 0.28 & 26.6 & 81.2 & 10.6 & 6.48 & 31.3 \\
Footwall rocks & 60.5 & 0.23 & 27.8 & 126.8 & 6.6 & 6.15 & 36.2 \\
Ore stone & 42.4 & 0.30 & 41.2 & 118.5 & 8.2 & 8.32 & 33.6 \\
Collapse body & 0.3 & 0.33 & 21.0 & 2.15 & 0.01 & 0.06 & 20 \\
Skarn & 43.6 & 0.23 & 30.9 & 62.6 & 35.0 & - & - \\
Filling body & 0.6 & 0.29 & 22.4 & 2.4 & $0.62^{[17]}$ & 28 & 0.6 \\
\hline
\end{tabular}

The geometric similarity ratio of similar simulation experiment is 1:600, so the corresponding physical and mechanical parameters should adjust the proportion. We built the numerical model of the same size as similar simulation experiment (Fig.5). The model size: the left height is $133 \mathrm{~cm}$, the right height is $117.5 \mathrm{~cm}$, the width is $163 \mathrm{~cm}$ and the thickness is $20.5 \mathrm{~cm}$. The bottom of the model is fixed, and both sides are constraint, the front and back are free surfaces.

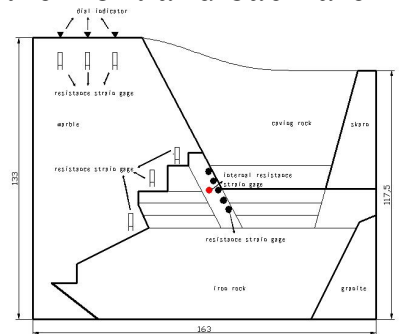

Fig.5 Combined Mining Model of Caving Method and Filling Method

In order to use the filling method of coal pillar, we plan to use the horizontal slice stoping and backfilling method or the upward horizontal slice stoping and backfilling method. To compare with the applicability of two mining methods, with the reality of mine, we observe the strain change of the contact zone in the process of coincident mining. Considering the actual and the mining in different mining methods, we mine in filling method and non-pillar sublevel caving mining method and at the same time we can use the filling method and non-pillar sublevel caving mining method, the following option is chosen:( Table 2). 
Table 2 Filling method of coal pillar

\begin{tabular}{l|l|l}
\hline scheme & stoping sequence & filling method described \\
\hline scheme 1 & $\mathrm{C} 1 \rightarrow \mathrm{C} 2 \rightarrow \mathrm{B} 1 \rightarrow \mathrm{C} 3 \rightarrow \mathrm{B} 2 \rightarrow \mathrm{C} 4 \rightarrow \mathrm{B} 3 \rightarrow \mathrm{C} 5$ & $\begin{array}{l}\text { the horizontal slice } \\
\text { stoping and backfilling } \\
\text { method }\end{array}$ \\
\hline scheme 2 & $\mathrm{C} 5 \rightarrow \mathrm{B} 1 \rightarrow \mathrm{C} 4 \rightarrow \mathrm{B} 2 \rightarrow \mathrm{C} 3 \rightarrow \mathrm{B} 3 \rightarrow \mathrm{C} 2 \rightarrow \mathrm{C} 1$ & $\begin{array}{l}\text { the upward horizontal } \\
\text { slice stoping and } \\
\text { backfilling method }\end{array}$ \\
\hline
\end{tabular}

Filling mining area can be divided into five layers, and the height of each layer is $6 \mathrm{~cm}$, the actual size is $46.8 \mathrm{~m}$, which should use the packing later directly. When the stoping listed in the stoping sequence, the recovery will be finished. The stoping sequence is finished when the mining is in the next sequence. And every time the filling only considers whether completes or not. If the roof is filling complete, the quality of the filling pulp satisfy with the requirements of the packing. After stoping sequence simulation every time, we can find out the maximum principal strain value in the maximum through two series of monitoring data. (figure 6 and figure 8 ).

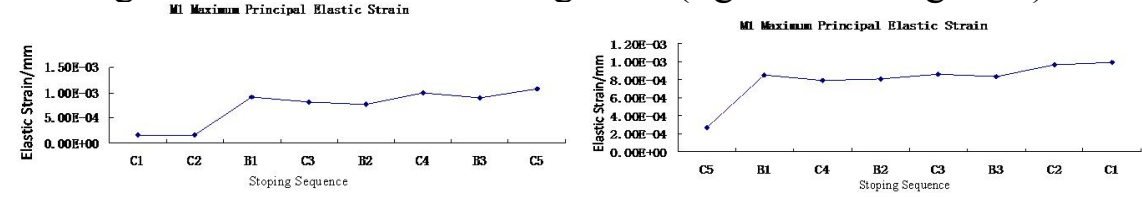

$\begin{array}{lll}\text { (a) scheme } 1 & \text { (b) scheme } 2\end{array}$

Fig. 6 The maximum principal strain value of the M1 series monitoring point in the case of the mining of the ore

It shows in figure 8 that the formation after stoping $\mathrm{C} 1$ and $\mathrm{C} 2$ mining area of the maximum principal strain is small, only $1.63 \mathrm{E}-04 \mathrm{~mm}$, when $\mathrm{C} 2$ filling is completed, go to mine $\mathrm{B} 1$, the maximum principal strain mutate to $9.14 \mathrm{e}-04$, strain values increased by 5.6 times. As the $\mathrm{C} 3$ of ore block stoping, the maximum principal strain from the upper part of the monitoring points 1 to 22 monitoring (Fig.9). That instructions C3 of ore block stoping helps to reduce the maximum principal strain. Although the series monitoring M1 is near to one end of caving method, the main point affects the deformation of contact zone near the side area of ore body caving mining technology is the ore block in filling mining from $\mathrm{C} 4$ and $\mathrm{C} 5$ mining maximum principal strain conditions. In figure 3, after stoping C5 and filling, then stoping B1, the larger mutations have also taken place in the maximum principal strain. Its value increases by 3.11 times, then the monitoring point of maximum of maximum principal strain changes more gently. Just after the abstraction of $\mathrm{C} 2$, the value has significantly increased a little, just 1.16 times. From the monitoring series of M1 maximum principal strain conditions, scheme 2 is better than scheme 1 .

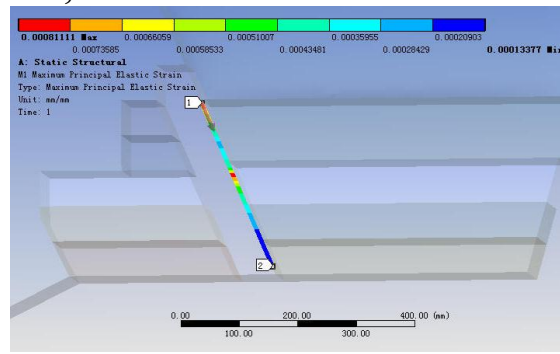

Fig.7 The main strain at each monitoring point of the $\mathrm{C} 3$ ore block after the completion of the mining 


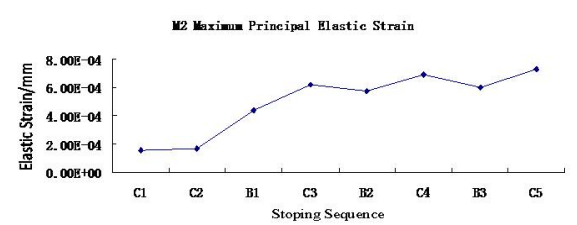

(a) scheme 1

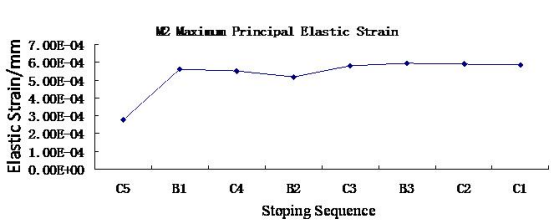

(b) scheme 2

Fig.8 The maximum principal strain value of the M2 series monitoring points in the case of the mining of the ore

In figure 8 , from $\mathrm{C} 1$ to $\mathrm{C} 3$, the maximum of the maximum principal strain value of the $\mathrm{M} 2$ series increased continually. From the maximum of the maximum principal strain value of stoping the $\mathrm{C} 1$ block $1.54 \mathrm{E}-04$ to the completion of $\mathrm{C} 36.21 \mathrm{e}-04$, that increases by 4.04 times. From the change trend of the back, the stoping of $\mathrm{C} 4$ and $\mathrm{C} 5$ ore block increases the maximum of maximum principal strain, the caving of B2 and B3 help reduce the strain value of the M2 series monitoring points instead. Showing in figure 5, the excavation of the C5 ore block to the caving of B1, the strain values increased by 2.01 times, after that the maximum of maximum principal strain changes smoothly and is just 5.59E-04(Table 3). In order to this, scheme 2 is better than scheme 1 .

To compare with pros and cons of two mining methods, we introduce the concept of complex divided difference to evaluate the stationary of occurred strain by the mean-squared error. The complex divided difference is:

$$
W=\left|\left(S_{1}-S_{2}\right) / \frac{\bar{X}_{1}-\bar{X}_{2}}{2}\right|
$$

Among them, $\mathrm{W}$ is for complex divided difference, S1 and S2 are for the mean-squared errors of the compared objects, $\bar{X}_{1}$ and $\bar{X}_{2}$ are for the mean of the compared objects.

For the M2 series monitoring points which are close to the side of filling method, and there's no obvious differences between the mean square errors of two types. The complex divided difference $\mathrm{W} 2$ is 0.229 . But for the M1 series monitoring points which are close to the side of caving method, mean square errors of two types of mining method have a big different. The complex divided difference $\mathrm{W} 1$ is 9.52 . All compound sent less than 1 stationary can be thought of the difference is not big. By the comparison of the complex divided difference, scheme 1 is slightly better than 2 for the comparison of the strain value of the M2 series monitoring points, but this just means that the stability difference is not big. For the comparison of the strain value of the M2 series monitoring points, scheme 1 is obviously better than the 2 . Finally, scheme 2 is better than the 1 by comprehensive quantitative comparison, under the upward horizontal slice stoping and backfilling mining method is superior to the horizontal slice stoping and backfilling mining method for safety pillar stoping.

Table 3 Comparis on of Strain Values at Two Different Filling Methods

\begin{tabular}{|c|c|c|c|c|c|c|c|c|}
\hline \multirow[b]{2}{*}{ scheme } & \multirow[b]{2}{*}{$\begin{array}{l}\text { stopping } \\
\text { sequence }\end{array}$} & \multirow[b]{2}{*}{$\begin{array}{l}\text { filling } \\
\text { describe }\end{array}$} & \multicolumn{3}{|c|}{ M1 series monitoring points } & \multicolumn{3}{|c|}{ M2 series monitoring points } \\
\hline & & & $\begin{array}{l}\text { typical } \\
\text { value } \\
/ \mathrm{mm}\end{array}$ & $\begin{array}{l}\text { mean-s quared } \\
\text { error } / \mathrm{mm}\end{array}$ & $\max . / \mathrm{mm}$ & $\begin{array}{l}\text { typical } \\
\text { value } \\
/ \mathrm{mm}\end{array}$ & $\begin{array}{l}\text { mean-s quared } \\
\text { error } / \mathrm{mm}\end{array}$ & $\max / \mathrm{mm}$ \\
\hline scheme 1 & $\begin{array}{l}\mathrm{C} 1 \rightarrow \mathrm{C} 2 \rightarrow \mathrm{B} \\
1 \rightarrow \mathrm{C} 3 \rightarrow \mathrm{B} 2 \\
\rightarrow \mathrm{C} 4 \rightarrow \mathrm{B} 3 \rightarrow \\
\mathrm{C} 5\end{array}$ & $\begin{array}{l}\text { top slicing } \\
\text { and caving }\end{array}$ & 0.000722 & 0.000948 & 0.001074 & 0.000497 & 0.001527 & 0.000732 \\
\hline scheme 2 & $\begin{array}{l}\mathrm{C} 5 \rightarrow \mathrm{B} 1 \rightarrow \mathrm{C} \\
4 \rightarrow \mathrm{B} 2 \rightarrow \mathrm{C} 3 \\
\rightarrow \mathrm{B} 3 \rightarrow \mathrm{C} 2 \rightarrow \\
\mathrm{C} 1\end{array}$ & $\begin{array}{l}\text { upward } \\
\text { slicing and } \\
\text { caving }\end{array}$ & 0.000797 & 0.000591 & 0.000993 & 0.000532 & 0.001531 & 0.000595 \\
\hline
\end{tabular}

With the combination of filling method and non-pillar sublevel caving mining method, and with the upward horizontal slice stoping and backfilling method and next to the horizontal slice stoping and backfilling method carrying on the numerical simulation, setting the main strain monitoring between the contact zone. The M2 series monitoring points which are in the right of the contact zone are caving close to the non-pillar sublevel caving mining method: the M2 series monitoring points which are in the left of the contact zone are close to the filling method mining area. Firstly simulate each step in the stoping sequence of each scheme to find out the maximum of 
the maximum principal strain value of the two series, then calculate the maximum of the mean, variance and the highest value in the maximum stoping sequence. Comparing two mining methods, although mean value of the scheme 1 is lower than scheme 2 for the maximum principal strain value of the M1 monitoring points ,Mean square error of scheme 2 is better than those of scheme 1 , the maximum value of the maximum value in scheme 2 is smaller than those of scheme 1 . For the maximum principal strain value of the M2 monitoring points, the mean value and the mean square error of the scheme 1 are both lower than 2, but the gap is small, and the maximum value of the maximum value in scheme 2 that is far smaller than those of scheme 1 . Finally, scheme 2 is better than the scheme 1 by comprehensive comparison, under the upward horizontal slice stoping and backfilling mining method is superior to the horizontal slice stoping and backfilling mining method for safety pillar stoping, under the upward horizontal slice stoping and backfilling mining method is superior to the horizontal slice stoping and backfilling mining method.

\section{The stoping sequence optimization of combined mining coordination}

Having determined the upward horizontal slice stoping and backfilling mining method of the safety pillar, we need to select and optimize according to the stoping sequence of the combined mining in the upward horizontal slice stoping and backfilling mining method and non-pillar sublevel caving mining method. Considering the safety pillar has huge quantities, only by choosing the combined mining of stoping sequence reasonably can it help to ensure the stability of the contact zone and safety production in mines.

At the same time, we carry on numerical simulation study, in order to further study the reasonable stoping sequence of combined mining in the horizontal slice stoping and backfilling mining method and non-pillar sublevel caving mining method. The study area is between -395 to

-500 meters levels. Below -500 meters levels of sublevel caving mining area, filling method is adopted according to the mining schedule. The stoping area of filling method is divided into five, namely, C1, C2, C3, C4 and C5, while the stoping area of caving method is divided into three, which are B1, B2, and B3.

Table 4 stoping sequence

\begin{tabular}{|c|c|c|}
\hline scheme & stoping sequence & instruction \\
\hline scheme a & $\mathrm{C} 5 / \mathrm{B} 1 / \mathrm{C} 4 / \mathrm{B} 2 / \mathrm{C} 3 / \mathrm{B} 3 / \mathrm{C} 2 / \mathrm{C} 1$ & $\begin{array}{c}\text { The proposed scheme } 2 \\
\text { continuous stoping two ore } \\
\text { block in filling method area,B3 }\end{array}$ \\
\hline scheme b & $\mathrm{C} 5 / \mathrm{B} 1 / \mathrm{C} 4 / \mathrm{C} 3 / \mathrm{B} 2 / \mathrm{C} 2 / \mathrm{C} 1 / \mathrm{B} 3$ & at last \\
\hline scheme c & $\mathrm{C} 5 / \mathrm{B} 1 / \mathrm{C} 4 / \mathrm{C} 3 / \mathrm{B} 2 / \mathrm{C} 2 / \mathrm{B} 3 / \mathrm{C} 1$ & $\begin{array}{l}\text { Stoping B3,C1atlast } \\
\text { Stoping B1 first, then } \\
\text { continuous stoning two ore }\end{array}$ \\
\hline scheme d & $\mathrm{B} 1 / \mathrm{C} 5 / \mathrm{B} 2 / \mathrm{C} 4 / \mathrm{C} 3 / \mathrm{B} 3 / \mathrm{C} 2 / \mathrm{C} 1$ & block in filling method area \\
\hline scheme e & $\mathrm{B} 1 / \mathrm{C} 5 / \mathrm{B} 2 / \mathrm{C} 4 / \mathrm{B} 3 / \mathrm{C} 3 / \mathrm{C} 2 / \mathrm{C} 1$ & $\begin{array}{l}\text { Stoping B1 first,Interval mining } \\
\text { in two mining methods }\end{array}$ \\
\hline
\end{tabular}

To further optimize the stoping sequence of combined mining in two methods, five different stoping schemes have been worked out (Table 4) with a combination of the mining production capacity in two methods which have already formed the relevant experience. Scheme a is the proposed method of horizontal blanking level cut under hand stoping and backfilling. To improve the efficiency of the stoping sequence simulation, scheme $b$ and $c$, scheme $d$ and e are compared with respectively.

\section{The comparison of scheme $b$ and scheme $c$}

For scheme $\mathrm{b}$ and $\mathrm{c}$, the rotation happens in the stoping sequence of the filling zone $\mathrm{C} 1$ and the caving zone B3, so it's necessary to compare the maximum value of maximum principal strain in a series of monitoring points formed by the two mining series monitoring. For either the series monitoring points of M1 or M2, the maximum value of scheme $\mathrm{c}$ is smaller than that of scheme $\mathrm{b}$ (Table 5), thus scheme $\mathrm{c}$ is better than scheme $\mathrm{b}$. 
Table 5 Comparison of maximum values of maximum principal strain in two

\begin{tabular}{|c|c|c|c|c|c|}
\hline scheme & $\begin{array}{l}\text { Comparison of the } \\
\text { content }\end{array}$ & \multicolumn{2}{|c|}{ the M1 series monitoring points } & \multicolumn{2}{|c|}{$\begin{array}{l}\text { the M2 series monitoring } \\
\text { points }\end{array}$} \\
\hline \multirow{3}{*}{ scheme b } & Stoping & $\mathrm{C} 1$ & B3 & $\mathrm{C} 1$ & B3 \\
\hline & $\begin{array}{l}\text { the most value } \\
/ \mathrm{mm}\end{array}$ & $9.92 \mathrm{E}-04$ & $9.93 \mathrm{E}-04$ & 5.95E-04 & $5.88 \mathrm{E}-04$ \\
\hline & the position & 24 & 24 & 46 & $46 、 47$ \\
\hline \multirow{3}{*}{ scheme c } & stoping & B3 & $\mathrm{C} 1$ & B3 & $\mathrm{C} 1$ \\
\hline & $\begin{array}{l}\text { the most value } \\
/ \mathrm{mm}\end{array}$ & $9.60 \mathrm{E}-04$ & $9.93 \mathrm{E}-04$ & 5.92E-04 & $5.85 \mathrm{E}-04$ \\
\hline & the position & 24 & 24 & 46 & $46 、 47$ \\
\hline
\end{tabular}

The comparison of scheme $d$ and scheme $e$

For scheme $\mathrm{d}$ and e, there is a transfer in the stoping of C3 and B3, so it only takes to compare the maximum value of maximum principal in a series of monitoring points formed by the two mining. For scheme d, as for the maximum value of the two series monitoring points, the maximum value in the former stoping is larger than that of scheme e. The differences between M1 and M2 series monitoring points are $0.53 \mathrm{E}-04 \mathrm{~mm}$ and $0.10-04 \mathrm{~mm}$ respectively. But after the second stoping, the maximum value of scheme $d$ is less than that of scheme e, the differences of M1 and M2 series monitoring points are $0.22-04 \mathrm{~mm}$ and $0.14-04 \mathrm{~mm}$ respectively (Table 6). It shows that both schemes have their own advantages and disadvantages. Considering that the M1 series monitoring points are in caving zone, the deformation influences the surface cleaning plant greatly, and for the maximum value of maximum principal in the first stoping, the maximum value of scheme $d$ is larger. Therefore, scheme e is superior to scheme $b$ by comprehensive consideration.

Table 6 Comparison of maximum values of maximum principal strain in two

\begin{tabular}{l|l|l|l|l|l}
\hline \multirow{2}{*}{ scheme } & $\begin{array}{l}\text { Comparison } \\
\text { of the content }\end{array}$ & $\begin{array}{l}\text { the M1 series monitoring } \\
\text { points }\end{array}$ & $\begin{array}{l}\text { the M2 series monitoring } \\
\text { points }\end{array}$ \\
\hline \multirow{4}{*}{ scheme d } & stoping & C3 & B3 & C3 & B3 \\
\cline { 2 - 6 } & $\begin{array}{l}\text { the most value } \\
\text { /mm }\end{array}$ & $8.59 \mathrm{E}-04$ & $8.32 \mathrm{E}-04$ & $5.79 \mathrm{E}-04$ & $5.95 \mathrm{E}-04$ \\
\cline { 2 - 6 } & the position & 24 & 24 & 46 & 46 \\
\hline \multirow{5}{*}{ scheme e } & stoping & $\mathrm{B} 3$ & $\mathrm{C} 3$ & $\mathrm{~B} 3$ & $\mathrm{C} 3$ \\
\cline { 2 - 6 } & $\begin{array}{l}\text { the most value } \\
\text { /mm }\end{array}$ & $8.06 \mathrm{E}-04$ & $8.54 \mathrm{E}-04$ & $5.69 \mathrm{E}-04$ & $6.09 \mathrm{E}-04$ \\
\cline { 2 - 6 } & the position & 2 & 24 & 46 & 46 \\
\hline
\end{tabular}

The comparison of scheme $a, c$ and $e$

In all five schemes, scheme $\mathrm{b}$ and $\mathrm{d}$ are eliminated, and in the remaining schemes, since differences between scheme a and c only lie in four different stoping, they are compared first to improve the comparative efficiency. 
Table 7 The comparison of the maximum value of the strain in the recovery of scheme a and scheme c

\begin{tabular}{|c|c|c|c|c|c|c|c|c|c|}
\hline scheme & $\begin{array}{c}\text { Comparison } \\
\text { of the } \\
\text { content }\end{array}$ & the & $\begin{array}{r}\text { [1 seri } \\
\text { p }\end{array}$ & $\begin{array}{l}\text { moni } \\
\text { its }\end{array}$ & ring & & 12ser & $\begin{array}{l}\text { monit } \\
\text { ints }\end{array}$ & ing \\
\hline \multirow{3}{*}{ Scheme a } & stoping & $\mathrm{B} 2$ & $\mathrm{C} 3$ & B3 & $\mathrm{C} 2$ & $\mathrm{~B} 2$ & C3 & B3 & $\mathrm{C} 2$ \\
\hline & $\begin{array}{l}\text { the most } \\
\text { value/ } \\
\text { E- } 04 \mathrm{~mm}\end{array}$ & 8.11 & 8.59 & 8.32 & 9.65 & 5.18 & 5.79 & 5.95 & 5.89 \\
\hline & the position & 2 & 24 & 24 & 24 & 46 & 46 & 46 & 46 \\
\hline \multirow{3}{*}{ scheme c } & stoping & $\mathrm{C} 3$ & $\mathrm{~B} 2$ & $\mathrm{C} 2$ & B3 & $\mathrm{C} 3$ & $\mathrm{~B} 2$ & $\mathrm{C} 2$ & B3 \\
\hline & $\begin{array}{l}\text { the most } \\
\text { value/ } \\
\text { E- } 04 \mathrm{~mm}\end{array}$ & 8.81 & 8.38 & 9.67 & 9.60 & 5.53 & 5.65 & $5.88 \mathrm{E}$ & 5.92 \\
\hline & the position & 24 & 24 & 24 & 24 & 39 & 46 & 46 & 46 \\
\hline
\end{tabular}

Table 7 shows that the two schemes have their own advantages and disadvantages. To the M1 series monitoring point, the maximum and average value of four stoping are $9.65 \mathrm{E}-04 \mathrm{~mm}$ and 8.67E-04mm in scheme a, but those are $9.67 \mathrm{E}-04 \mathrm{~mm}$ and $9.12 \mathrm{E}-04$ in scheme c. Comparing the maximum and mean value, scheme a is superior to $\mathrm{c}$.

Finally compare to scheme a and scheme e.

Table 8 The maximum value of the strain in the recovery of scheme a and scheme e

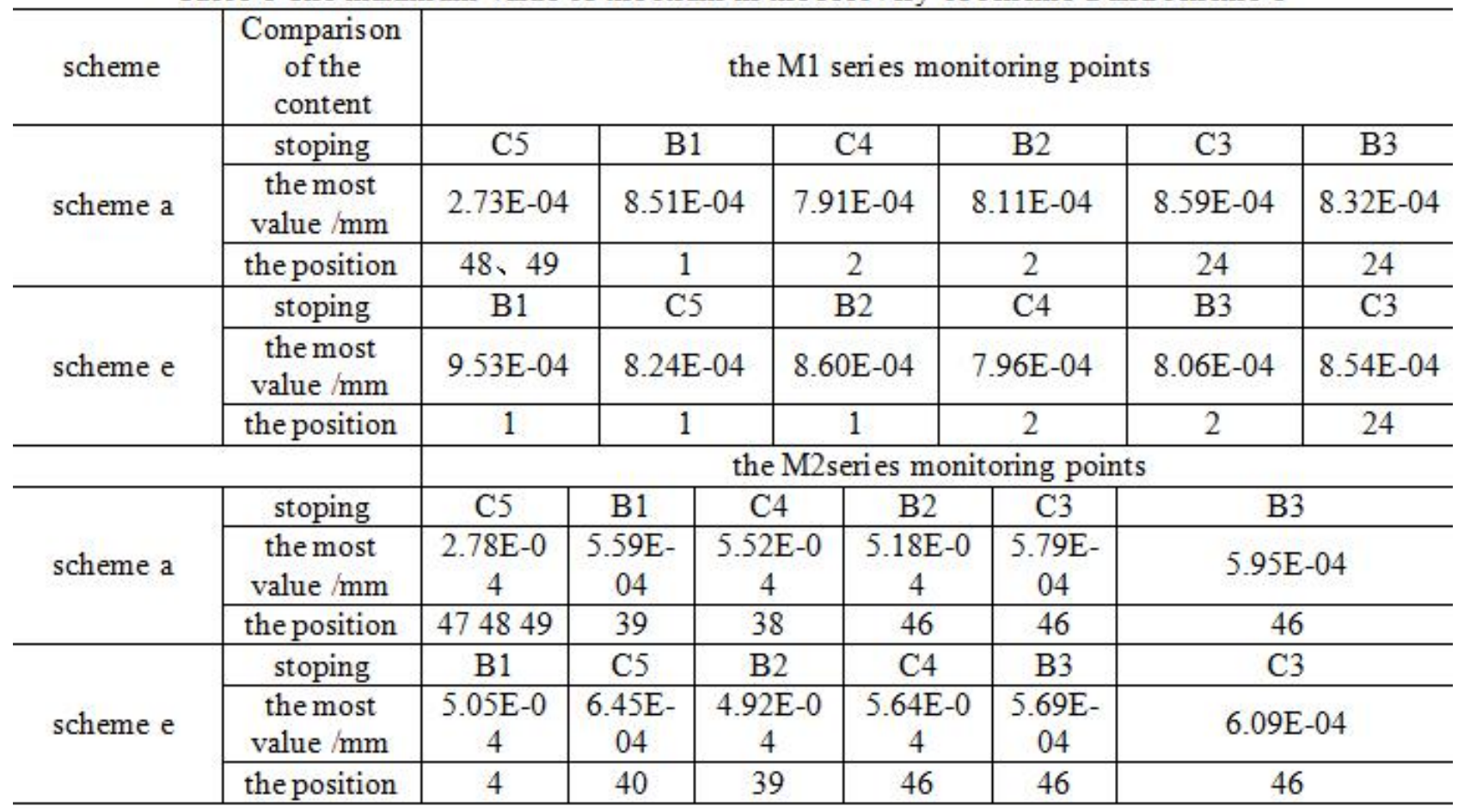

To the M1 series monitoring point, the maximum and average value of the maximum value in scheme a are $7.37 \mathrm{E}-04 \mathrm{~m}$ and $8.59 \mathrm{E}-04 \mathrm{~mm}$ respectively, but those are $9.53 \mathrm{E}-04 \mathrm{~mm}$ and $8.49 \mathrm{E}-04 \mathrm{~mm}$ respectively, hence scheme a is superior to scheme c apparently. To the M2 series monitoring point, the maximum and average value of the maximum value in scheme a are $5.95 \mathrm{E}-04 \mathrm{~mm}$ (Table. 8 ) and $5.14 \mathrm{E}-04 \mathrm{~mm}$ respectively, with a contrast to $6.45 \mathrm{E}-04 \mathrm{~mm}$ and $5.64 \mathrm{E}-04 \mathrm{~mm}$ respectively in scheme e, accordingly, scheme a is superior to scheme e. In a word, scheme a is superior to scheme e.

\section{The impact on the contact zone from the combined mining}

Before the stoping, the minimum value of the maximum principal strain in M1 series monitoring points is $9.45 \mathrm{E}-05 \mathrm{~mm}$, appearing on the NO.15 monitoring point, and the maximum 
value of the maximum principal strain is $1.53 \mathrm{E}-04 \mathrm{~mm}$, appearing on the NO.49 monitoring point, from fig.9. After the stoping, the minimum value of the maximum principal strain in M1 Series monitoring points is $2.47 \mathrm{E}-04 \mathrm{~mm}$, appearing on the NO.15 monitoring point, and the maximum value of the maximum principal strain is $9.93 \mathrm{E}-04 \mathrm{~mm}$, appearing on the NO.24 monitoring point, from fig.9.

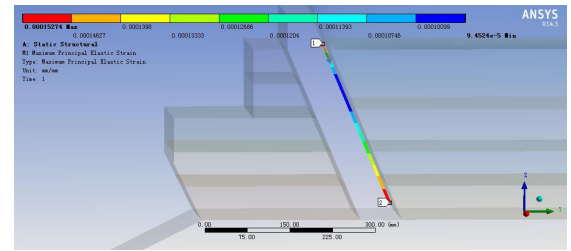

(a) No backfill

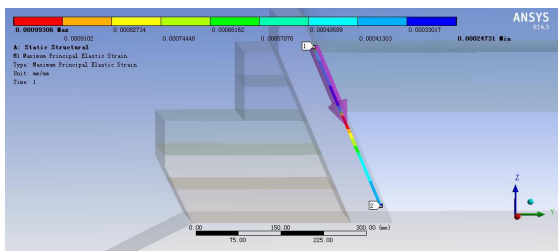

(b) Backfill

Fig.9 Maximum principal strain cloud of the pre-mining inspection line

After the stoping, the principal strain values in M1 and M2 Series monitoring points are showing in figure 10 to 12 .

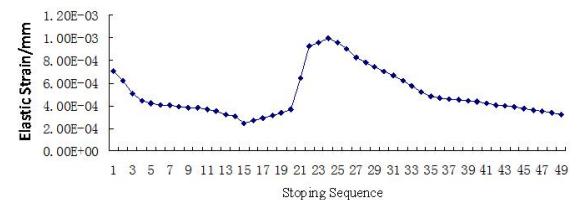

(a) M1

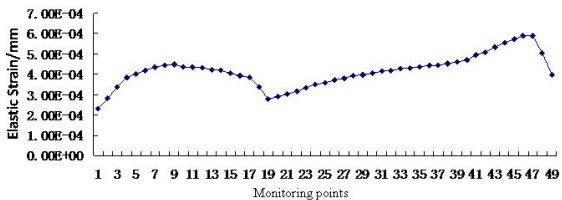

(b)M2

Fig.10 The series of monitoring points of the maximum principal strain value
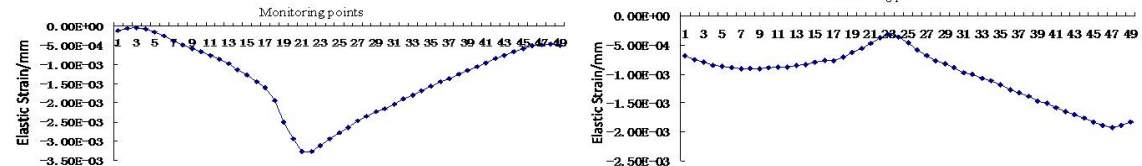

(a)M1 (b)M2

Fig.11 Minimum Principal Strain Value of Series Monitoring Point
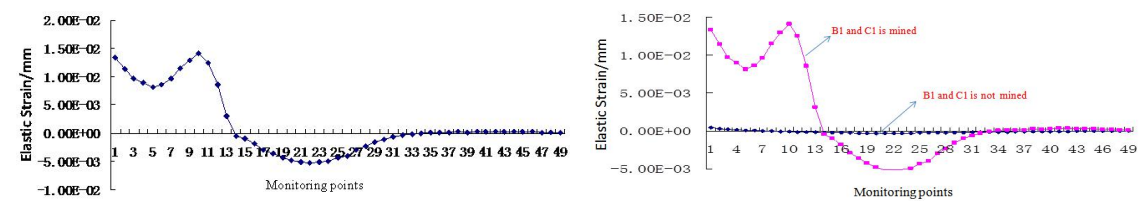

(a) No backfill

(b) Backfill

Fig.12 Series of monitoring points M2 of the maximum principal stress value

After the stoping in B1 and B2, the monitoring points which are close to the ground pressure on-line in M2 Series monitoring points are from NO. 1 to NO.10, the value is between 8.17E-03MPa and1.41E-02MPa.

By comparing the monitoring data on line, ground pressure on-line monitoring system in the corresponding stress value of the changes that take place after stoping, shown in fig.16. In about half a year, the ground pressure value of online monitoring increases from 1.25 $\mathrm{MPa}$ to $1.50 \mathrm{MPa}$, the ground pressure increases by $0.25 \mathrm{MPa}$ (Fig.13), this little change matches with the calculation results of numerical simulation. It shows that a selected typical profile, and an established numerical model to simulate the stability of the contact zone combined mining are reliable.

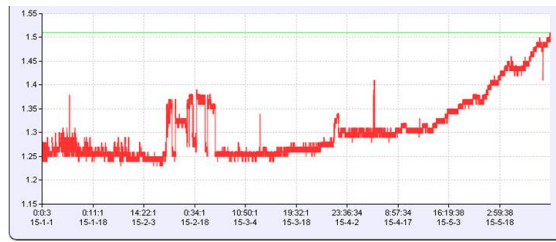

Fig.13 On-line Monitoring Stress Curve of Ground Pressure 


\section{Conclusions}

1) Comparing the stress changes by the numerical simulation of the undeveloped and developing mining to the data of On-line monitoring stress system of the scene, the data are consistent. It shows that the established numerical model is in line with the actual, it can provide guidance and methods for the following selection of the filling method and the optimization of stoping sequence in the combined mining.

2) To simplify the contact zone of combined mining for the mechanical model of beam and spring constraint, by the calculation of maximum deflection and maximum shear stress, we can better explain the contact mechanics mechanism.

3) By comparing the numerical simulation and introducing the divided difference comparison method, we can find that the upward horizontal slice stoping and backfilling mining method is superior to the horizontal slice stoping and backfilling mining method for safety pillar stoping.

4) By simulate comparing five stoping sequence in the combined mining, the B1 / C4 / C5 / B2 / C3 / B3 / C2 / C1 stoping sequence of scheme a is in favor of the stability of the contact zone combined mining, it illustrates that staggering the coordinate and combined mining is better.

\section{Acknowledgements}

This work was financially supported by the national natural science foundation of China(Foundation items: No. 51604195)

\section{References}

[1]Mingsong Pei, Mengguo Xu, Ping Wang, et al. Study on Surface Deformation Based on the Coexsitence of Two Methods in Chengchao Iron Mine[J].Metal Mine,2015(12):148-152. (in chinese)

[2]Fuding Mei, Rukun Wang, Hong Xia. Application Study of Caving Method and Filling Method Combined Mining in Jin Shandian Iron Mine[J]. Metal Mine,2013(10):21-24. (in chinese)

[3]Lei Deng. Study on Mining Method of Transition Region from Caving to Filling Method in West-wing of Cheng chao Iron Mine[D].Wuhan:Wuhan University of Science and Technology,2015:9. (in chinese)

[4]Bing Jiang, Shan Wu. Study on mining technology of transition zone from sublevel caving to backfilling method in Daye Iron Mine[J]. Nonferrous Metals(Mining Section),2014,66(3):23-25. (in chinese)

[5]Wenbin Xu, Weidong Song, Haiwen Wan,et al. Study on Mining Sequence and Ore-drawing Control Technique of High-stage Backfill Mining[J]. Metal Mine,2011(6):13-15,28. (in chinese)

[6]Zhiliang He, Daguo Wang, Bin Li,et al. Analysis of the Stopes Stability in Different Stages of Stoping and Filling under Complicated Stress Condition[J]. Metal Mine,2016(6):24-31. (in chinese)

[7]Chi Zhang, Deqiang Fang, Yu Chen, et al. Xianglushan Tungsten Large mined-out area filling stoping method optimization research [J].Nonferrous Metal Engineering,2014,4(3):59-61. (in chinese)

[8]Bin Han, Jianxun Wu, Peng Wang,et al. Appfication Research of Large Diameter Long Hole Drilling with Backfill Mining Method[J]. Metal Mine,2014(6):16-20. (in chinese)

[9]Long An, Shuai Xu, Shaofeng Ren, et al. Study on Design and Optimization of Milling Sequence for Deep and Large Ore Body[J].Journal of northeastern University(Natural Science), 2013, 34(11):1642-1646. (in chinese)

[10]Biyong Zhu, Wei Yang, Xinmin Wang, et al. The Permanent Pillar Arrangement and the Stoping Sequence under Large-scale Backfill Body[J]. Metal Mine,2015(7):21-24. (in chinese)

[11]Yicheng Ye, Yaobin Shi, Qihu Wang,et al. Experimental study of deformation of wall rock and stoping sequence in mining gently inclined and multilayer deposits by backfill mining[J]. Journal of Mining \& Safety Engineering,2015,32(3):407-413. (in chinese) 
[12]Liangliang Zhou. JinshanDian Iron Ore Deep Filling Stope Structure Parameters And Mining Sequence Optimization Research[D].Wuhan:Wuhan University of Science and Technology,2014:46-53. (in chinese)

[13]Mengguo Xu, Mingxu Wang, Ping Wang, et al. Stoping sequence optimization analysis and high stress control based on evaluation of safety factors[J]. IM\&P,2013(13):24-29. (in chinese)

[14]Shishen Song, Mingchun Guo, Peng Yan,et al. Experimental study on non-pillar sublevel caving mining method in Na Lin gold mine[J]. GOLD,2010,31(10):33-37. (in chinese)

[15]Liguan Wang, Zhuli Ren, Chuanpeng Pan,et al. Optimization Analysis of Stope Mining Sequence Based on Mixed Integer Programming[J].The Chinese Journal of Nonferrous Metals, 2016,26(1):173-179. (in chinese)

[16]Guitong Yang. Elastic mechanics[M]. Beijing:HIGHER EDUCATION PRESS,1998:148. (in chinese)

[17]Mingsong Pei. Study on Mining Scheme and Surface Stability based on the Combination of Filling Method and Caving Method in Chengchao Iron Mine[D]. Wuhan:Wuhan University of Science and Technology,2016:38. (in chinese) 